\title{
Giant Left Ventricular Aneurysm
}

\section{Benan Çağlayan}

Department of Pulmonology, Dr. Lütfi Kurdar Kartal Education and Research Hospital, İstanbul, Turkey

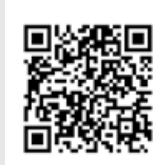

Received Date: 17.03.2014 Accepted Date: 17.03.2014

\section{Address for correspondence}

Benan Çağlayan, Department of Pulmonology, Dr. Lütfi Kırdar Kartal Education and Research Hospital, İstanbul, Turkey E-mail: benancag@gmail.com

(C) Copyright 2014 Turkish Respiratory Society (TRS) Eurasian J Pulmonol 2014

DOI: 10.5152/ejp.2014.04127

-Available online at www.eurasianjpulmonol.com

A 60-year-old male patient presented to our clinic with shortness of breath, coughing, and haemoptysis. In the medical history of the patient, it was seen that his complaints had been ongoing for about 5-6 years, he suffered from wheezy respiration as well as shortness of breath, and he had been diagnosed with chronic obstructive pulmonary disease (COPD) and proposed inhaler treatment. The patient had recently described increased shortness of breath and minimal haemoptysis, and stated that his complaints increased while sleeping at night yet felt better when he elevated his head with a high pillow. The patient had previously smoked up to 60 packs.year of cigarettes and he is still an active smoker. He defined no accompanying disease other than chronic obstructive pulmonary disease. On physical examination of the respiratory system, rare inspiratory rales and common rhoncus were heard in the bilateral basals. On examination of the circulatory system, it was found that peak heart rate shifted to the lateral and was rhythmic as $128 / \mathrm{min}$. No pathological finding was observed in physical examinations of other systems, except pretibial edema. Pulmonary function tests revealed the results of FVC: $64 \%, \mathrm{FEV}_{1}: 26 \%$ and $\mathrm{FEV}_{1} / \mathrm{FVC}: 32$.

Posteroanterior pulmonary radiography demonstrated that the cardiothoracic ratio was increased and that the left ventricle almost completely occupied the lower part of the left hemithorax. More-

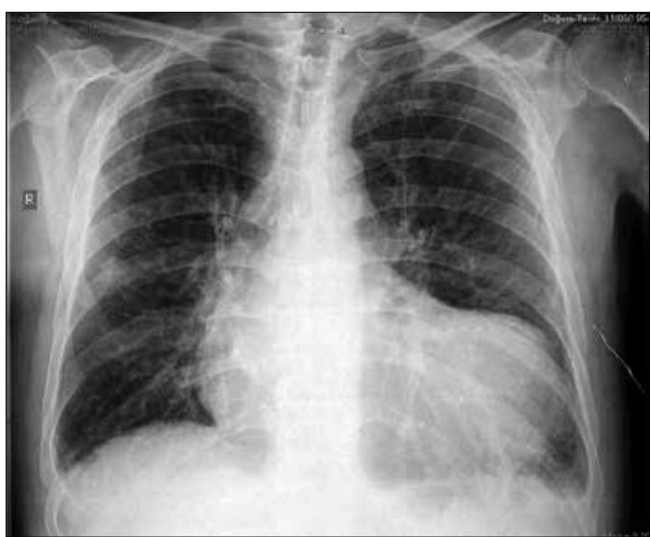

Figure 1. On posteroanterior pulmonary radiography of the patient, a solitary nodule with the diameter of $2 \mathrm{~cm}$ and superimposition on the right fifth anterior costa with an opacity related to aneurysmatic extension of left ventricle was observed occupying the lower part of the left hemithorax almost completely

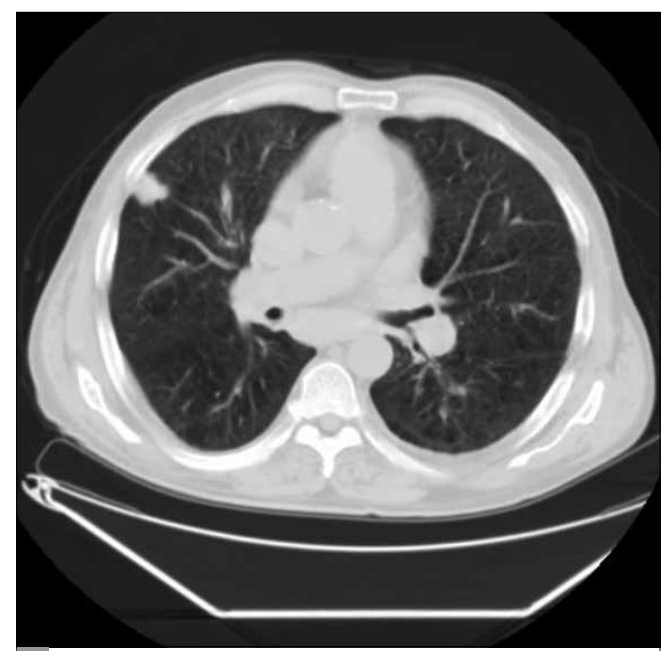

Figure 2. On the parenchymal window image of computed tomography of the thorax, a subpleural lobule-contoured nodule was observed in the right middle lobe 


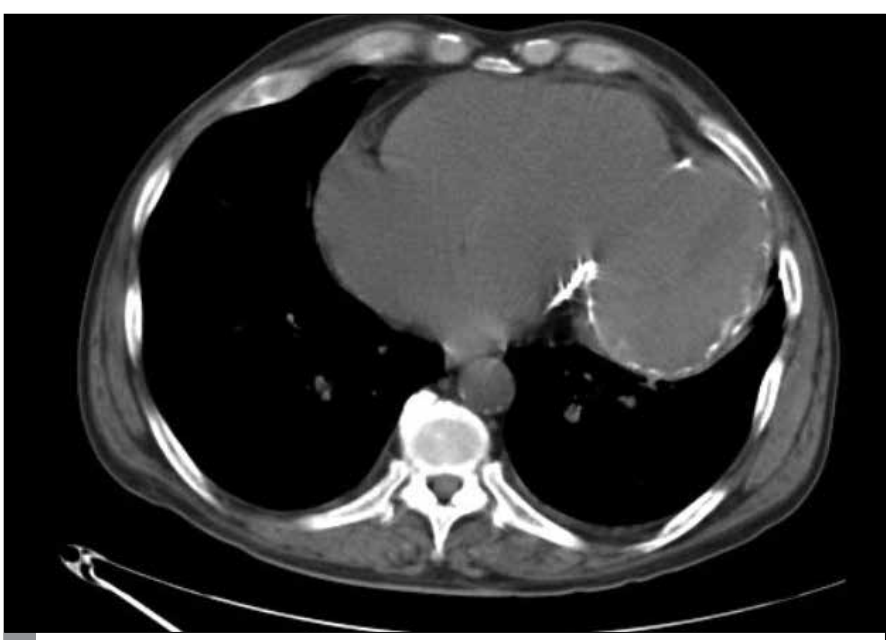

Figure 3. On the mediastinal window, a 91×112 mm-sized and left ventricle-associated aneurysmatic extension with local calcifications on its wall was observed over, a round opacity with a diameter of $2 \mathrm{~cm}$ and an unclear border, localised in the periphery, was detected in the right middle zone (Figure 1). Computed tomography evaluation revealed generalised centriacinar emphysema, subpleural nodule with lobule contour in the right middle lobe, and left ventricle-associated aneurysmatic extension with local calcifications on its wall, which was $91 \times 112 \mathrm{~mm}$ at its widest point (Figure 2,3)., The ejection fraction rate was found to be $25 \%$ in echocardiography, and an aneurysmatic extension larger than $10 \mathrm{~cm}$ and adjacent to the left ventricle was observed. PET/CT evaluation demonstrated that metabolic activity of the nodule was increased and multiple lymph nodes with high fluorodeoxyglucose (FDG) affinity were present in the mediastinum. Due to high cardiopulmonary risk, the patient was not exposed to invasive examination and no treatment was considered for malignancy.

Informed Consent: Written informed consent was obtained from patient who participated in this study. 